\title{
Standardization of Insurance Services as a Factor in Improving Their Quality
}

\author{
Tatyana D. Odinokova*, Elena B. Dvoryadkina
}

\author{
Ural State University of Economics, Yekaterinburg, Russia \\ *Corresponding author. Email: tdo17@yandex.ru
}

\begin{abstract}
The popularity of an insurance product depends on many parameters, but the most significant of them is the quality of the service provided. Insurance services are related to financial services and are complex enough for the population to understand the specifics of their provision and, as practice has shown, many consumers face certain difficulties in choosing an insurance product, choosing its components (insurance conditions) and purchasing it. Development of standard insurance products makes it easier for consumers to select services owing to standardization of the process and availability of insurance information. As the experience of the Massachusetts Health Insurance Exchange has shown, voluntary standards play an important role in increasing transparency and improving industry practices while promoting competition between insurers by enabling consumers of insurance services to match their insurance product offerings. In this article, the authors disclose the features of standardization process development in the Russian insurance market, examine the problems and prospects for the development of insurance services' standardization, taking into account financial capabilities of Russian insurers and the measures taken by the main regulators of the insurance market (Bank of Russia and the self-regulatory organization of the All-Russian Union of Insurers). The Russian experience is interesting because, in conditions of low demand for insurance services, rising regulatory burden on the insurance business and oligopolization of the market, as well as activation of integration processes of the economy in the international space, insurance companies find various ways to survive, and one of them is to offer standard ('boxed') insurance products. This measure, as a new technology of offering insurance products, has received support from the Bank of Russia and in the near future is to receive a stimulating effect by allowing insurance companies to place their standard insurance products on the regulator's marketplace.
\end{abstract}

Keywords: insurance organization, standardization of insurance processes, insurance market regulation, standardization of insurance services, quality of insurance services, aggregator, marketplace

\section{INTRODUCTION}

Given a high regulatory burden on the insurance business and a low demand for insurance products, Russian insurance companies are severely limited in their ability to create and promote insurance products that consider the individualism of consumers, and to carry out their costs to improve the quality of their sales. Many insurance organizations are more concerned with ensuring financial stability of the business and meeting the requirements of the state regulator, than with the issue of improving the quality of insurance transactions for consumers. In this connection, the issue of transparency of an insurance transaction arises, including consumer awareness of the terms of an insurance contract and the fulfillment of obligations undertaken by insurance organizations to consumers of insurance products. A perceived quality of an insurance product largely depends on the quality of interaction of the insured with the insurance intermediary and the completeness of the information provided. In a competitive market, an offer of higher quality products is a prerequisite for a successful insurance business. The offer of higher quality products entails an increase in costs, but these costs pay off, since the most complete customer satisfaction leads to their steady commitment to the insurance organization and increased sales of insurance products. However, in the conditions of market oligopolization [1], the quality of insurance products is paid attention, mainly, only by the state supervisory authority to protect the interests of insured persons. Therefore, in Russia, not many Russian insurance companies have decided to voluntarily create and implement internal standards that are aimed at ensuring transparency of all processes in the company.

In the spring of 2019, a number of standardization provisions were passed in Russia and, as a result, there was a decrease in premium collection. This was largely due to a change in the strategy of insurance intermediaries 
(primarily commercial banks), since the introduced standards aimed at transparency of an insurance transaction required additional costs for intermediaries to train their specialists in the specifics of selling insurance products. Therefore, many insurance intermediaries reoriented their sales departments to other, less regulated financial instruments.

Despite a high potential of using standardization in insurance, as mentioned above, many insurance business representatives perceive this measure negatively, since the application of standards will require changes in all business processes of insurers, including both the insurance products and their sale channels, which in turn will lead to the need for new investments in updating the business. In order to be prepared for these changes, insurers will need sources of financing and relevant knowledge and skills in this direction. As a result, insurance companies may encounter several problems that may negatively affect their performance and position.

From this perspective, studying the problems of introducing and using standardization of products plays a strategic role for insurance companies, because today the choice of an insurance company by citizens is often determined by the cost of the insurance policy and for many of them an insurance policy is not affordable. Determining a fair and correct price for an insurance product (also called pricing) is crucial for both policyholders and insurance companies.

Currently, there aren't many papers devoted to standardization of insurance services. This is because this issue is extremely promising for many countries, and the interest in it has an increasing trend. However, it should be noted that the papers are mainly devoted to the relationship of the parties of the transaction. Firstly, these include papers aimed at studying the influence of public confidence on the conclusion of insurance transactions [2]. The qualitative and quantitative assessment of insurance transactions is largely determined by the trust in insurance companies, which people and enterprises provide. Confidence, in turn, depends on the completeness and reliability of the information provided both about the activities of an insurance company, and about the concluded insurance transaction. Secondly, a significant number of papers are dedicated to the study of a relationship between service quality and customer satisfaction $[3,4,5,6]$. The perceived quality of service and the satisfaction are mainly conceptualized as separate structures, which does not give a general understanding of their relationship [6]. Thirdly, it is necessary to note studies on testing methods for assessing the perceived quality of service and the intention to make a repeated purchase of the service [7]. The results show that (1) a performance-based measure of service quality can be an improved measure of service quality design, (2) service quality is a precursor to customer satisfaction, (3) customer satisfaction has a significant impact on a purchase, (4) service quality has less impact on purchase intentions than customer satisfaction. The implications for managers and future research are being discussed. Fourthly, studies devoted to the demand model for insurance products based on expected utility [8,9], the results of which confirm that a person will buy full insurance if a fair price is established in relation to his risk [9]. Fifthly, studies aimed at studying the impact of standardization on decision-making about insurance conditions $[10,11,12,13,14]$. When choosing insurance programs, the population faces various difficulties [10]. Despite the abundance of scientific papers devoted to various aspects of service quality management, there are practically no works devoted to studying the specifics of managing the quality of insurance services and the problems of using standardization of insurance products in the modern economy.

An objective of this scientific study is to identify the problems of standardization of insurance services in Russia and develop proposals for their elimination.

\section{RESEARCH METHODS}

To achieve the research objective, an induction method was used, in which, based on a detailed study of the problems of standardization implementation by insurance companies, proposals were formulated to create conditions aimed at increasing the population's demand for standard insurance products. Besides, when performing the research, generally accepted methods of scientific search and cognition were used, such as: dialectic, historical, and comparative methods.

\section{RESULTS}

In most leading countries of the world, the quality problem is in the center of attention of economic interests of both individual citizens and companies, and a state. A similar strategy should be a priority in Russia. Only in this case, our country will be able to enter the world community not as a raw materials appendage, but as a harmoniously developed power with a high technological level that meets the challenges of the 21 st century.

In this regard, issues of ensuring and improving the quality of goods and services should be addressed both at the market level and at the level of state policy. В Российской In the Russian Federation, measures aimed at formation and implementation of modern state policy in the field of technical regulation and quality are the most important factor in the implementation of national interests in such areas of the state's activity as economic, social, military, international, and environmental. Thus, this policy will ensure the country's integration into the global economy and prepare Russia for joining the World Trade Organization (WTO) as an equal partner.

Currently, Russia is at a stage of implementing integration processes in the international space. 2021 will be the year of Russia's accession to the WTO, which will lead to increased competition in all spheres and sectors of the national economy, since expansion of the market allows the buyer to choose goods from almost all world 
manufacturers. As a result, each of them will compete with others in a specific area. In such conditions, only those who provide high quality at a low price will survive. As a result, only those organizations that can implement this will remain on the market.

In recent years, all these factors have led to transformation processes in all sectors, including the insurance industry, where these processes are largely reinforced by market oligopolization. In the struggle for 'survival' in the national insurance market, many insurance companies did not set themselves the task of managing the quality of the services provided. However, the standards introduced by the state supervisory authority in 2019 should radically change the processes occurring in the insurance market.

A modern development of the insurance market should not mislead insurance companies. According to a social survey, the level of confidence in insurers for most of the population is still extremely low. Today, Russian insurance companies need to build a business focused on the consumer, on his interests, on high standards of quality of insurance products, and services, since transnational insurance companies that plan to enter the Russian insurance market after opening the borders already have an effective management system, including a customeroriented sales system. As a result, these companies will draw the attention of Russian consumers of insurance services very quickly.

In market conditions, the guarantee that the company will survive and will successfully develop is its ability to meet the requirements of consumers. This is facilitated, first, by the properties and quality of the products. 'In marketing, quality is the degree of customer satisfaction, where it acts as an integral characteristic of the competitiveness of a product and is evaluated by a set of consumer parameters of the product. In this regard, it is necessary to create a supporting quality system of corporate standards. The quality system is an integral element of any corporate structure management system' [15].

Currently, the degree of urgency of the problem of improving the quality of insurance services is increasing, due to the following factors:

firstly, the growth in the requirements of scientific and technological progress dictates significant qualitative changes;

secondly, the complication of relations within the insurance market, between the insurance and other segments of the financial market, as well as interstate relations occurs due to the further deepening of integration processes;

thirdly, the processes of globalization of the economy lead to increased competition between enterprises of different countries for sales markets in virtually a single world space;

fourthly, an increase in the level of quality of insurance services is also important from the point of view of solving not only economic and technical problems, but also social ones;

fifthly, an increase in the level of quality of insurance services is significant from the standpoint of confidence of the population and enterprises in insurance organizations.
Thus, the solution to the problem of improving the quality of insurance services will increase the competitiveness of both the insurance organization and the country's insurance industry in the international space.

In turn, the quality of insurance services depends on factors such as:

1) competencies and professionalism of specialists of an insurance organization, including selling insurance products;

2) financial and material capabilities of an insurance organization;

3) image and business reputation of an insurance company;

4) state of the legal framework governing the relationship of the parties to an insurance transaction;

5) availability and status of certification and/or standardization of insurance products and services.

International and domestic theory and practice have proven that it is possible to really manage the quality of insurance services and increase their competitiveness in the Russian and world markets if an insurance technology is based on a comprehensive system of standards that maximally covers all aspects and stages of the insurance process.

In some countries, compulsory certification is applied to insurance services, in others voluntary or compulsory standardization is provided for. In Russia, mandatory certification of insurance services is not provided for by law. The issue of standardization in the country was raised several times and some issues were resolved partially. Thus, in 1998-2002 13 standard insurance rules were introduced, which mainly concerned compulsory types of insurance, and were based on a voluntary nature of their application.

In May 2019, two basic standards entered into force: the basic standard for insurance companies performing operations in the financial market; basic standard for protecting the rights and interests of individuals and legal entities that receive financial services provided by members of self-regulating organizations that combine insurance organizations. These standards are mandatory not only for insurance companies, but also for insurance intermediaries, including commercial banks. The standards were adopted in the framework of combating misselling (misleading customers). Such violations were observed more often when selling unit-linked life insurance policies (ULLI), sellers in banks often offered them as a complete replacement for deposits. The new standards force policy sellers to inform buyers about the lack of guarantees of profitability and protection of the rights of insured persons, as well as financial consequences in the event of early termination of the ULLI contract.

The emergence and implementation of new standards led to the following consequences:

1) a decrease in the number of sales of insurance products and a drop in the rate of collecting premiums for ULLI;

2) reduced interest of insurance intermediaries, primarily commercial banks, in sales of ULLI policies;

3) increase in the number of complaints of dissatisfied policyholders to the Insurance Supervisory Authority 
about previously concluded insurance transactions through commercial banks;

4) improving citizens' awareness of the features of ULLI products;

5) low confidence indicators for insurance companies.

To ensure a high level of sales, an insurance product must contain one or more simple and understandable for the consumer ideas that justify its purchase; surpass similar products of competitors in its consumer properties; and not stand out among similar products due to the higher price. The increase in the number of sales of insurance products is greatly facilitated by the simplification of customers' understanding of its economic mechanism, as well as the benefits provided by the product [16].

In recent years, many insurance companies have developed and implemented a standard (common or boxed) insurance products. These standard (boxed) insurance products are quite popular among the population. However, it is very difficult to get insurance payments for them due to a non-transparent mechanism for settling claims.

As practice has shown, many consumers face certain difficulties when entering into an insurance contract, such as:

1) the need to find a compromise in deciding both your choice in favor of insurance and the choice of components of an insurance product (premium, amount of insurance coverage, types of insurance risks);

2) lack of understanding of the essential terms of an insurance contract [10] due to a large volume of information and its overload with specific terminology.

Digitalization of the economy cannot ignore insurance services, and as part of it, insurance organizations are forced to transform their business processes, including organization of sales. However, not all insurance companies are financially, technologically and informatively able to implement a digital sales platform. Soon, a marketplace (electronic trading platform) will be created based on the Bank of Russia, where insurance companies will be given an opportunity to sell standard insurance products. As we can see, standardization of insurance services helps consumers of insurance services, first, to understand current offers, focusing on the terms of insurance, and second, to determine the provider of insurance services, focusing on its business reputation.

Thus, selling standard insurance products through marketplace allows you to separate such processes from each other:

1) selecting characteristics of an insurance product from the supplier's choice;

2) the supplier's choice from the choice of costs associated with the purchase of an insurance product, including the deductible.

As a result, insurance organizations will compete for business on a transparent, level playing field, and cost reductions and sales will provide the population with a choice of insurance programs to meet their needs [10], and the architecture of choice can affect market results of an insurance company [11].
Thus, participation of insurance companies on the marketplace, on the one hand, will increase the confidence of consumers in insurance services, on the other hand, will make it possible to use a cheaper (compared to banking) sales channel, and will also allow to optimize business processes, focusing them on expanding the range of covered insurance risks. A striking example of such participation of insurance companies is functioning of the marketplace based on the [11] Massachusetts Health Insurance Exchange.

In addition, by allowing policyholders to choose possible characteristics of insurance programs on the marketplace, insurance companies will be able to see their needs and, accordingly, by offering them, they will be able to ensure the influx of new consumers of insurance services [12].

Standardization of insurance services is one of the components of comprehensive standardization, which provides an opportunity to make the insurance business more transparent for consumers, and therefore increases confidence of policyholders.

It should be noted that an insurance product has nominal and real quality. 'Nominal' quality is reflected in an insurance contract and in the insurer's advertising products, and 'real' quality is found out only at the stage of settlement of an insurance claim, i.e. it is deferred in time from the moment of purchase of this guarantee, and, therefore, depends entirely on the payment policy of the insurer and clarity of the business process of settlement of losses and related business processes. At the same time, promotion of an insurance product is based on building trust in the product and its issuer (insurer). In this regard, standardization of claim settlements is particularly relevant, and since a subject cannot reliably judge the quality of a product at the time of its purchase, the 'expected quality' is mainly subjective, and is largely determined by the accompanying explanations of the company's specialists and insurance agents about the purchased product. In such a way, when we are talking about a large scale standard product (Compulsory Motor Third Party Liability, Fully Comprehensive Insurance, accident insurance, etc.), an insurance company within the acquisition business processes being developed, should pay special attention to the process of fully informing the insured about the specifics of the purchased product, including such things as 'exceptions from coverage', 'deductibles', 'terms and procedure of payment', 'compensation of damage', 'recognition of an insurance event', etc. Otherwise, this will lead to the formation of inflated expectations of the client (policyholder), and, consequently, to a sharp negativism and antagonism at the claim handling stage.

Therefore, at present, there is an urgent question of the need for comprehensive standardization that will be 'focused on the following tasks:

- rational use of labor and material resources in insurance;

- increase of labor productivity, improvement of insurance services quality using domestic and foreign achievements in the field of insurance research; 
- optimization of tariff policy (which increases financial reliability of insurance companies);

- improvement of insurance companies' management;

- development of international cooperation and increasing competitiveness of the Russian insurance market' [13].

Thus, the comprehensive standardization of insurance services, which is aimed at consumers, allows us to significantly improve efficiency and quality of insurance, as well as supervision over it.

Summarizing the above, we would like to emphasize that the issue of insurance services quality depends on the following points:

1. quality of relationships with consumers of insurance services;

2. completeness, clarity and transparency of terms of an insurance contract and performance indicators of an insurance company;

3. accessibility and operability of the user interface in the case of purchasing an insurance product without a consultant's participation;

4. closeness of the list of documents and the speed of a claim settlement when an insurance event occurs.

5. openness, transparency and responsibility of insurance intermediaries in the system of insurance relations.

We hope that in the medium term, the market itself will develop necessary mechanisms for external and internal regulation of relations between policyholders and insurers in the provision of quality insurance products and services, the standardization of which will act as a certain lever for the effective organization of their sales.

Despite the fact that standardization of insurance services is of strategic importance for insurance companies as a factor that allows them to improve their quality, few insurance companies are going in this direction, because it involves additional problems:

1. not all types of insurance can be standardized;

2. development and implementation of standard ('boxed') insurance products leads to an increase in the load on processing and customer service and, consequently, to an increase in the costs of an insurance company;

3. presence of companies that do not want to go into the segment of 'cheap' insurance;

4. presence of companies (primarily regional) that will not be able to develop competitive standard insurance products due to high costs of running their business;

5. presence of a relatively small number of aggregators that allow to compare the offers of standard insurance services from different companies;

6. lack of a legal framework for promoting standard insurance products through aggregators, including the marketplace;

7. presence of certain technological difficulties in integrating information bases of insurance organizations and an aggregator, including the marketplace;

8. influence of a specific mentality of the population, due to the opinion that cheap does not mean of high quality;

9. low competition of insurance companies in the national market due to its oligopolization;
10. presence of certain difficulties in determining a fair and correct price for an insurance product (also called pricing), since it (the price) is crucial for both policyholders and insurance companies;

11. presence of certain difficulties for consumers in determining an insurance company as a service provider based on its brand, since many citizens have not heard of insurance companies at all and, if they have, they can only name two or three companies, not the fact that they will be the best;

12. difficulty in making any changes to standardized insurance products during the validity of the concluded contract;

13. complexity of including innovative developments in standardized insurance products;

14. application of the deductible in an insurance contract is not always clear to consumers of services;

15. difficulty of achieving a single standard of after-sales service for policyholders in all branches of an insurance company, taking into account regional specifics;

16. commercialization of the insurance business and, as a result, difficulty of maintaining a reasonable balance between the interests of insurance companies and policyholders, due to an ambiguous interpretation of the 'effectiveness of insurance services' for each of the parties to the transaction.

Given the above, several measures should be implemented to develop standard insurance products in Russia. First, insurance companies, together with the Self-Regulating Organization of the All-Russian Union of Insurers (SRO ARUI), conduct Public relations (PR) events on a permanent basis [17] in order to form a favorable public opinion regarding insurance products, including standardized forms of them; secondly, the Bank of Russia, as a regulator of the Russian insurance market, should join forces with the SRO ARUI in creating necessary conditions for ensuring transparency of the insurance business. This proposal can be implemented by creating a single database of policyholders and insured persons in order to detect fraudulent activities, as well as creating a single information platform on the number of complaints filed with the Bank of Russia and the number of legal proceedings (claims) against each insurance company; third, we need to activate all policyholders in terms of increasing the pace of biometric data connection. It should also be noted that the insurance companies should take maximum measures to ensure information security in order to protect customers' personal data from unscrupulous users, since in the near future, as a result of digital technologies, the risk of manipulation or misuse of other people's data will be one of the most dangerous risks not only in Russia, but also abroad; fourth, the Bank of Russia, SRO ARUI and insurance companies should take action to speed up the launch of the marketplace based on the Bank of Russia with the possibility of selecting the content of an insurance product and further comparability of the selected plan by service providers (insurance companies) and the cost of the policyholder; fifth, expanding the list of insurance types that fall under possibility of creating a standardized form (for example, credit insurance, 
mortgage insurance, voluntary medical insurance) and possibility of purchasing them through the marketplace without 'linking' to insurance companies accredited by commercial banks. This measure will allow policyholders to be free in choosing an insurer that acts as a guarantor of the fulfillment of its obligations to a commercial bank, and thus increase the confidence of consumers of services in insurance companies; Sixthly, it is necessary for SRO ARUI to develop standards for insurance services, including standard plans of insurance products, standards of product information and documentation between the parties to an insurance transaction, as well as standards of scenarios for settlement of claims under each plan of an insurance product to protect the interests of insurance consumers. Voluntary standards are usually developed by consensus of all stakeholders, subject to unrestricted open consultation and systematic review to ensure their continued validity [14].

If a policyholder knows that he is comparing equivalent insurance products, he will make a more reasoned decision based on loyalty and the brand of an insurance company.

Thus, the use of standard insurance products allows to systematize work in the field of service quality improvement, which will allow to objectively assess satisfaction of consumers and other participants of insurance relations and outline ways to develop them. Only if insurance services' quality is continuously improved, an insurer has a chance to maintain and strengthen its position in the market.

\section{CONCLUSION}

An obvious simplicity and efficiency of standardization has a certain appeal. However, there are types of insurance for which it is difficult to develop standard conditions, such as life insurance. However, no matter how good the standard insurance products are, they also have some disadvantages that we have discussed above. A standardized form is not always the best answer, but it is a unique response of insurance companies to changes in market conditions. If a current demand for insurance products in Russia is reduced due to the lack of free funds among most of the population (low incomes) and strengthening of oligopolistic trends in the market development, then, accordingly, the development and implementation of standard insurance products is one of the best possible decisions that insurance companies could make. In this situation, the availability of insurance products for the population is a step towards the consumer, which is to create a trusting relationship that is implemented through completeness, clarity and transparency of the terms of an insurance contract and consulting services. However, by taking this step, you need to create conditions to retain the client, and this is the second step - to justify the client's confidence, i.e. to fulfill obligations to them in the event of an insurance event. It is at this step that the true face of insurers and the mission with which they came to work in the insurance market will be shown. Unfortunately, at present, not many insurance companies that are leaders in this direction can boast about their integrity without judicial activity.

At this stage, the justification of trust, which is implemented by settling claims for claimed insurance cases, which are important for determining the prospects for insurance development in the country, largely depends on the quality of customer service: speed, care and correct behavior in customer service. To ensure this process, the digital technologies being introduced (BigData, biometrics, automation, insurance telematics) are a good help. It is the quality of this process that determines customer's satisfaction with insurance services and the prospect of purchase (renewal) of an insurance product, loyalty to the insurance company and recommendations for their relatives and friends.

Analyzing the specifics of the use of standard insurance products in Russia, it should be noted that presence of many problems hinders their development, but they will be resolved as soon as the insurance industry experiences another crisis due to the growing regulatory burden on insurers, and due to the coverage of an increasing number of consumers with digital technology products, the necessary ground for new insurance products will be prepared. Perhaps all forecasts regarding the pace of insurance development in Russia will be achievable.

Taking into account the above points, the authors suggest that Russian insurance companies, focusing on the positive foreign experience and taking into account peculiarities of the mentality of Russian citizens, continue to work on the introduction of standard insurance products, including entering into partnership agreements with aggregators or participating in the marketplace of the Bank of Russia. Participation in such events will create unique offers that will attract new consumers of insurance services and increase the competitive advantages of insurance companies.

\section{CONFIRMATION}

Once again, we would like to note that implementation of the proposed measures for the development of standard insurance products will create more favorable conditions for the population to make decisions on concluding insurance contracts, and, as a result, will affect the development of the Russian insurance market. Thus, the success of eliminating problems in the application of standard insurance products in the activities of insurance companies will increase the quality of services provided and, consequently, the confidence of the Russian population in insurance companies.

\section{REFERENCES}

[1] Odinokova T.D., Istomina N.A. (2018) Transition of insurance market to oligopoly: Benefits and drawbacks, Academy of Accounting and Financial Studies Jobrnal (AAFSJ). Volume 22, Issue 3, 2018 
[11] Keith M. Marzilli Ericson, Amanda Starc, How product standardization affects choice: Evidence from the Massachusetts Health Insurance Exchange, Journal of Health Economics, Volume 50, 2016, Pages 71-85, ISSN 0167-6296, https://doi.org/10.1016/j.jhealeco.2016.09.005. (http://www.sciencedirect.com/science/article/pii/S0167 629616302156)

[12] Abaluck, Jason, and Jonathan Gruber. 2011. "Choice Inconsistencies among the Elderly: Evidence from Plan Choice in the Medicare Part D Program." American Economic Review, 101 (4): 1180-1210. DOI: 10.1257/aer.101.4.1180

[13] Besfamilnaya L.V., Tsyganov A.A. Standardization Methodology in the Field of Insurance // Finance, 2002, No. 6.

[14] Opportunities for Standardsin Insurance. BSI and Z/Yen Group, 2014.

https://webcache.googleusercontent.com/search?q=cach e:HXZnY-

L4fLQJ:https://www.bsigroup.com/LocalFiles/enGB/standards/BSI-Standards-research-reportOpportunities-for-Standards-in-Insurance-UKEN.pdf $+\& c d=3 \& h l=r u \& c t=c \operatorname{lnk} \& g l=r u$.

[15] Soloviev S.S. Safe Recreation and Tourism. M.: Academia, 2008. 288 p.

[16] Babenko E.Yu. Standardization of Insurance Products - Prospect of Insurance Marketing Development // Questions of Modern Science and Practice. University named after V.I. Vernadskiy. 2008. Volume 1. No. 3 (13). pp. 170-173

[17] Odinokova T.D. (2019), Russian Insurance Market: Federal, Regional Measures and SelfRegulation, Journal of Advanced Research in Law and Economics, Volume IX, Issue 8(38), Winter 2018, August 2019. DOI:

https://doi.org/10.14505//jarle.v9.8(38).20 